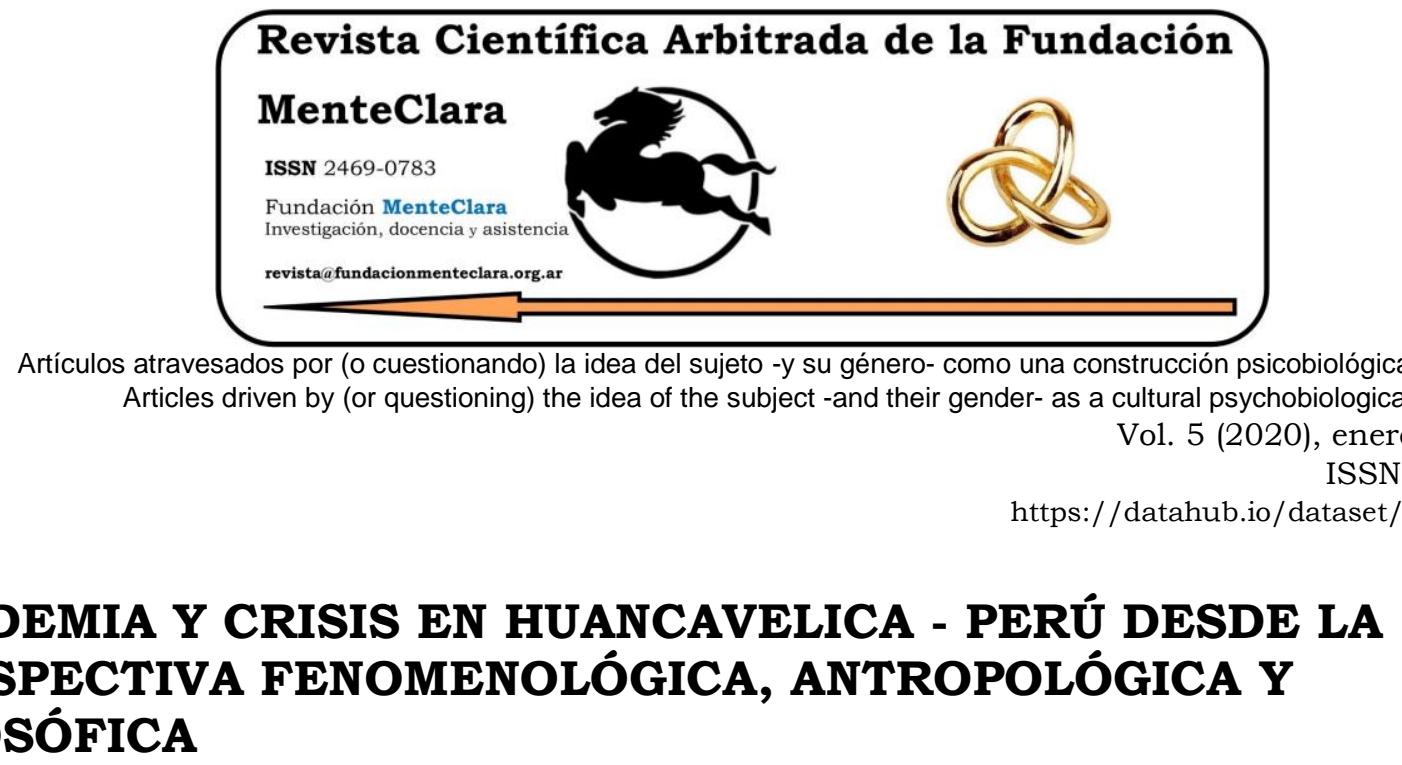

\title{
PANDEMIA Y CRISIS EN HUANCAVELICA - PERÚ DESDE LA PERSPECTIVA FENOMENOLÓGICA, ANTROPOLÓGICA Y FILOSÓFICA
}

\author{
PANDEMIC AND CRISIS IN HUANCAVELICA - PERU FROM THE \\ PHENOMENOLOGICAL, ANTHROPOLOGICAL AND PHILOSOPHICAL PERSPECTIVE
}

Ricardo Arango Olarte ${ }^{1}$, Aparicio Chanca Flores ${ }^{2}$, Antonio Nahuincopa Arango ${ }^{3}$

Cómo citar este artículo / Citation: Arango Olarte R., Chanca Flores A. \& Nahuincopa Arango A. (2020). "Pandemia y crisis en Huancavelica - Perú desde la perspectiva fenomenológica, antropológica y filosófica". Revista Científica Arbitrada de la Fundación MenteClara, Vol. 5 (174). DOI: https://doi.org/10.32351/rca.v5.174

Copyright: (C) 2020 RCAFMC. Este artículo de acceso abierto es distribuido bajo los términos de la licencia Creative Commons Attribution 4.0 International License (CC BY 4.0). Recibido: 09/10/2020. Aceptado: 14/10/2020 Publicación online: 16/10/2020

Conflicto de intereses: Ninguno que declarar.

\section{Resumen}

El COVID-19, a diferencia de las otras regiones del país, llegó a la tierra del Mercurio con el éxodo de la ciudad al campo, de los hijos residentes en la capital, llevando consigo el Coronavirus que contagió masivamente a la población. En este artículo abordamos y analizamos, desde una visión tripartita, la crisis del hecho fenoménico, ocasión para reflexionar sobre temas relevantes -que van más allá del enfoque económico o biopolítico- para el ser humano: el sentido de la vida, el allin o sumaq kawsay (el buen vivir); la condición humana de la mortalidad; cómo articular el aislamiento social con la salud mental y la incertidumbre; el individualismo frente al colectivismo andino. Finalmente, abordamos sobre la corrupción en la sanidad,

\footnotetext{
${ }^{1}$ Universidad Nacional del Centro del Perú, Facultad de Antropología, Perú.

ricardoarango9@gmail.com

${ }^{2}$ Universidad Nacional del Centro del Perú, Facultad de Antropología, Perú. achanca@uncp.edu.pe

${ }^{3}$ Universidad de Navarra, España. antonio3560@gmail.com
} 
educación e incluso en el apoyo humanitario. Sabiendo que aquéllas son pilares fundamentales para el desarrollo de la familia, el pueblo y la nación. Temas relevantes que compartimos desde los Andes Centrales.

\section{Abstract}

COVID-19, unlike the other regions of the country, reached the land of Mercury with the exodus from the city to the countryside, of the children residing in the capital, carrying with them the Coronavirus that massively infected the population. In this article we address and analyze, from a tripartite perspective, the crisis of the phenomenal event, an opportunity to reflect on relevant issues -which go beyond the economic or biopolitical approach-for the human being: the meaning of life, the allin or sumaq kawsay (good living); the human condition of mortality; how to articulate social isolation with mental health and uncertainty; individualism versus Andean collectivism. Finally, we address corruption in health, education and even in humanitarian support. Knowing that these are fundamental pillars for the development of the family, the people and the nation. Relevant topics that we share from the Central Andes.

Palabras Claves: pandemia; crisis; colectivismo andino; corrupción; salud mentalemociones; cientificismo

Keywords: pandemic; crisis; Andean collectivism; corruption; mental health-emotions, scientism 


\section{Introducción}

Es paradójica la situación de la pandemia generada por el COVID-19 en el Perú, fuimos los primeros en aplicar la cuarentena en Latinoamérica, sin embargo, somos el país con mayor tasa de contagios y muertes a nivel mundial. El 06 de marzo de 2020, llega el primer portador positivo del virus de Wuhan a la capital. Nueve dias después, el presidente de la República, Martin Vizcarra Cornejo, declara en Estado de Emergencia Nacional, mediante un Decreto Supremo N 044-2020-PC.

La pandemia se ha expandido a nivel mundial a pasos agigantados. Y tiene su peculiaridad. Por una parte, ha trastocado el "orden" global o mundial al paralizarla de un momento a otro; trayendo consigo el caos en muchos aspectos. Por otra, marca en la historia, "un antes y un después" de este virus. Pandemia, viene precisamente de dos voces griegas "pan", todo y "demos", pueblo, esto es, "todo el pueblo". El verdadero nombre del COVID-19, según (Badiou 2020, 68), es SARS-2, “Severe Acute Respiratory Syndrom 2". La existencia de la epidemia SARS1 se manifestó en el 2003, en aquel entonces era "la primera enfermedad desconocida del siglo XXI". Después de diecisiete años, aún se desconoce sobre el origen y causa.

En este artículo, a raíz de la pandemia, abordamos temas relevantes y trascendentales que necesitan un análisis y reflexión sobre el valor de la vida, el sentido de la muerte, si vale la pena vivir en este mundo, si todo culmina con la muerte o existe otra realidad más allá de este mundo empírico. Es una mirada tripartita sugerente: que nos ayudará plantear algunas cuestiones. Desde la perspectiva fenomenológica, basada en la experiencia propia o ajena, de cómo se manifiesta la enfermedad en Huancavelica. Así mismo, conviene resaltar, la existencia de algunos matices en el comportamiento de los pobladores tanto en la Sierra como 
en la Costa y la Selva. Cada región tiene su propia idiosincrasia, cultura, idioma y costumbres. La mirada antropológica, desarrolla el Coronavirus y los distintos comportamientos humanos tanto el individualismo y el colectivismo andino y las diferentes posturas frente a este problema que viene generando el COVID-19. Asimismo, el modo de reaccionar en la convivencia del aislamiento social y sus consecuencias. Finalmente, la filosofia nos ayudará a vislumbrar esta situación como de una montaña alta, oteando los problemas radicales del hombre: ¿de dónde venimos y a dónde vamos? ¿Qué significa que somos seres mortales? ¿Cómo afrontar la muerte? Cuál es el estatuto ontológico del COVID-19, qué clase de ser vivo es y qué problemas traerá para la filosofia, sabiendo que después de esta crisis la situación de la vida no será como antes.

\section{La COVID-19 en Huancavelica}

Esta ciudad también es conocida como "La Villa rica de Oropesa", está a 3660 msnm ubicada en la cadena de la sierra central del Perú, enclavado en las altas montañas. Es uno de los departamentos más pobres del país. Actualmente es azotada por el COVID-19 que llegó a este lugar, aunque un poco más tarde que a las otras regiones. Esta situación es insostenible por la cantidad de contagios y muertos a pesar de la cuarentena focalizada de más de seis meses. A esta, se suma las condiciones paupérrimas de pobreza, informalidad, el sistema de salud ineficiente, la ignorancia y la falta de liderazgo de algunas autoridades y la desorganización, son factores que no coadyuvan al control del avance de la pandemia y solo estar a la espera de la vacuna, que no se sabe cuándo llegará.

Es necesario mencionar también el comportamiento de la población, que aún no ha asumido la tarea de ciudadano responsable, activo y 
participativo. Más por el contrario ha demostrado su irresponsabilidad, al no respetar los protocolos establecidos sobre bioseguridad: el uso correcto de las mascarillas, el cuidado del distanciamiento social, y el adecuado lavado de las manos. Llegamos a los centros de abastos y/o mercados nos aglomeramos; organizamos campeonatos en nuestras comunidades, pensando que allí no va a llegar; organizamos reuniones familiares sin control, pensando que no va a pasar nada con una postura de carpe diem. Estas actitudes y acciones mezquinas han contribuido que esto sea un caldo de cultivo para el aumento desmesurado del contagio masivo en toda la localidad. Al fin de cuentas, son pequeños detalles; pero tiene gran importancia a la hora de la práctica y de modo especial en esta coyuntura; ya que las cosas grandes están hechas a base de piezas pequeñas.

Como consecuencia de todo esto, tanto el hospital del Ministerio de Salud -MINSA como el Essalud "con mayor capacidad resolutiva" han colapsado. La realidad de estos nosocomios, es que nunca han estado preparados, mucho menos implementados para poder tratar a los pacientes con COVID-19. Donde muchas veces, los pacientes llegan a morir, por falta de atención del personal de salud con profesionalismo y servicialidad, además de no brindar las condiciones necesarias para su recuperación. Donde se observa el estado calamitoso de la Unidad de Vigilancia Intensiva, (UVI). Así mismo, es desesperante observar entre los afectados, por ejemplo, no saber la situación del paciente, pues, hay un ambiente de hermetismo, es decir, no brindan ninguna información al respecto, a lo lejos observas avisos como éste: "cualquier información del paciente a partir de las cinco de la tarde". Llegada la hora indicada tampoco hay respuesta. ¡O que el personal médico está ocupado, será a las siete de la noche! La angustia y la desesperación, carcomen por estas actitudes. Así mismo, la impaciencia y la impotencia empiezan a 
manifestarse entre los familiares. Todo esto expresa la fenomenología del sufrimiento humano. Ante este hecho tan dramático, conviene preguntarse: ¿Cuál es el plan de contingencia?, ¿Dónde está el personal médico idóneo o capacitado?, ¿Cuentan con los recursos necesarios para atenderlos?

\section{La crisis de la pandemia en sus diversos aspectos.}

La crisis en general, es un desorden, algo que no va bien y es provisional. Sólo esta noción amerita para un artículo (Boitano 2020, 11 29). Quién no tiene experiencia de crisis emocional, de pareja, vocacional, económica, sin embargo, el COVID- 19 literalmente ha generado una verdadera crisis en todos los aspectos que subsume las anteriores.

Como seres inteligentes, podemos pensar o reflexionar sobre la crisis de la pandemia con la ayuda de la fenomenología y la antropología filosófica, dicho de otro modo, qué nos pueden decir estos enfoques al respecto: afirmamos como idea central, que somos seres contingentes. Es decir, realmente existimos, pero podríamos haber no existido. Los seres humanos, por ende, con tantos talentos: la inteligencia, la riqueza y el poder, somos, al fin y al cabo, limitados por y en el tiempo-espacio, la enfermedad y nuestra misma naturaleza. Aunque para Leibniz este mundo es el mejor de los mundos posibles. Por otro lado, ¡Somos seres para la muerte! Esta enfermedad ha confirmado lo que estamos aseverando, puesto que ha sacado a relucir nuestras limitaciones en sus diversos aspectos o facetas: la salud, la economía, la gestión política, la educación. No es que no hay nada nuevo bajo el sol como manifiesta (Badiou 2020, 68). ¡Cómo no pasará nada! O como una cosa normal. Es un acontecimiento muy grande incluso supera una película de ciencia y ficción con la diferencia abismal que esto es real y aquella no. Esta 
pandemia está ocasionando reflexiones interesantes, sin embargo, se ha dejado a un lado temas relevantes y fundamentales de la existencia humana en sus diferentes dimensiones. Que todo no es lo económico: que el COVID-19 ha generado y dará un golpe al capitalismo (Žižek 2020, 21-28) o el contrario (Han 2020,110) señala que el coronavirus no vencerá a dicho sistema.

\subsection{El problema del éxodo de la ciudad al campo}

El día 16 de marzo del 2020, se decretó la suspensión del transporte interprovincial de pasajeros: terrestre, aéreo y fluvial. Los huancavelicanos residentes en la capital -Lima y en algunos departamentos- se quedaron en sus moradas, aunque quisieron viajar a sus tierras por el miedo de contagiarse por la presencia del COVID-19. Sin embargo, el segundo mensaje presidencial -diez días después de la suspensión del transporte- ampliaba el confinamiento, lo cual marcó "un antes y un después" en la emergencia sanitaria del país, por las consecuencias sociales que trajo: por un lado, se tenía que guardar el confinamiento social obligatorio, el cumplimiento de los protocolos de bioseguridad; por otra parte, se les iba agotando el dinero porque muchos de ellos vivían de su labor cotidiano e informal del día a día. Un mes sin trabajar significa ni un sol de ingreso para el hogar. Ya no tenían dinero para alimentarse y pagar el alquiler de sus cuartos. Por lo que, muchos fueron echados insensiblemente a la calle por sus deudas. Ante este panorama desolador, muchos de ellos tomaron la decisión de retornar a sus lugares de origen, encabezados por los huancavelicanos, especialmente de la zona rural $^{4}$. A esto se sumaron, también los que se quedaron varados en la capital por diversas circunstancias.

\footnotetext{
4 "Si nos quedamos aquí todos vamos a morir", dijo un joven al canal de televisión Frecuencia Latina, 14 de abril.
} 
Ante una eminente ola de migraciones no organizadas, el Poder ejecutivo, emitió la Resolución Ministerial N 097-2020-PCM, donde dispone que los Gobiernos Regionales, deben de elaborar un padrón, para el retorno organizado.

Con esta prerrogativa el Gobierno Regional, implementa la página web, con la finalidad de que las personas se puedan inscribir. Era un escenario adverso para el Gobierno Regional de Huancavelica; que se avecinaba una tormenta social y nada sencillo; la otra limitante es que en todo el país estaba en estado de emergencia sanitaria.

Ante ese hecho, muchas familias empezaron a inscribirse en el padrón habilitado en la página web del Gobierno Regional. Para ello se organizan mediante grupos de WhatsApp y las redes sociales, se juntan un grupo de personas para retornar. No obstante, al no poder ser considerado en el grupo "seleccionado"; otros deciden retornar simplemente por su cuenta utilizando otros medios.

En esta coyuntura, por ejemplo, un grupo de huancavelicanos, toman la decisión de caminar, enfrentándose a las diversas condiciones climáticas, poniendo en riesgo su salud y vida por las largas caminatas. Asi se pudo registrar a familias caminando por la carretera central, la vía los libertadores, caminos de herradura y otros, por la desesperación y la incertidumbre del momento. En esta odisea, cada uno tuvo que librar una batalla titánica, con la frase emblemática "sálvese quien pueda" 5 .

Así mismo, en el trayecto se encontraban con muchas personas, igual que ellos. Quienes tuvieron que afrontar y esquivar el control policial y militar en diversos tramos. Por evitar esto, tenían que cruzar ríos, trepar cerros y rodear poblaciones, cargando sus pertenencias e hijos menores.

\footnotetext{
${ }^{5}$ Gobernador Regional de Huancavelica Maciste Díaz Abad, realiza declaraciones a los diversos medios de comunicación, 14 de abril, exhortando a que "no venga, porque van a contagiar".
} 


\subsection{Dilema de la vida y la muerte}

El Coronavirus que azota a la humanidad es un hecho fenomenológico sin precedente. Por un lado, la pandemia -haciendo la suya-finiquita sin compasión, sin distinción de raza, sexo, religión o poder, con las vidas humanas. Por otra parte, la humanidad, -representada por las autoridades, personal de salud, policias, militares y serenazgo- hacen esfuerzos titánicos para no contagiarse y salvar vidas humanas. Es tan complejo este dilema "vida-muerte" (Guillen, 1994,148).

Desde la perspectiva fenomenológica, podemos afirmar cómo el COVID-19 cada día acaba con las vidas humanas sin excepción, y palpar en carne propia el dolor humano ante la pérdida de un miembro de la familia. Enterarnos que tan solo en 24 horas dos mil muertos en USA, la primera potencia del mundo! En Italia y España colapsaron los mejores hospitales. Esto nos parecía un sueño. En efecto, cuando se dio a conocer en Guayaquil. Ecuador -nuestro país vecino- muchos muertos en las calles, no imaginamos que lo sucedido nos tocaría en carne propia, aunque tardó en llegar a Huancavelica.

Y uno se cuestiona, ¿qué es lo que está pasando? ¿Qué hicimos mal? La muerte por COVID-19 va tocándonos de "puerta en puerta". Del mismo modo, se encuentran muchos hermanos nuestros en la unidad de cuidados intensivos (UCI); algunos son enfermos críticos reversibles y/o otros irreversibles; cuyas vidas dependen del personal de salud, que toma decisiones radicales. Otros no encuentran la cama UCI, muchos menos el oxígeno, las medicinas, cuyos precios fluctúan por las nubes, las clinicas que han convertido esta situación en bisnes. En esta guerra, ¿hasta qué punto es ético, quitar el respirador mecánico a un anciano y darle a un joven; o dejar morir a un pobre y tratar de salvar la vida a un 
rico? No debemos hacer distinciones para salvar la vida. ¡Todos debemos ser tratados con dignidad y merecemos vivir!

El hombre es la única criatura que sabe de su condición mortal: ¡que está hecho para vivir, mas, tiene que morirse! Esta situación, ¿no es nuestra contradicción, nuestro enigma? Si estamos hechos para vivir, ¿por qué tenemos que morirnos? La cuestión de la muerte es una certeza, incluso, nos atrevemos a manifestar, que es una verdad absoluta y evidente -no necesita una demostración- puesto que, un día vamos a dejar de existir y es algo doloroso para la familia. La pandemia nos confirma esta realidad por los miles de muertos que hay en el planeta. No sabemos el cuándo y el dónde, porque trasciende nuestro conocimiento. Y el cómo morir, creemos está en nosotros de alguna manera, pues, depende el modo de cómo vamos a asumir en ese momento, esto es, o bien con la confianza y tranquilidad o desesperación. Esto dependerá también fundamentalmente qué sentido hemos dado a nuestra vida. Algunos, ante esta situación de la muerte, buscaron la piedra filosofal por la inmortalidad. Pero hasta ahora, aun no se ha encontrado. ¿La ciencia podrá descubrir algún día, la solución para la muerte?

Esta pandemia es una crisis que atañe fundamentalmente a la vida y su dignidad: en la forma en qué, cómo y quién muere (Arocha 2020, 96). Algunos pensadores abordaron la cuestión de la muerte con vehemencia. Según (Noemi 2007, 47) la muerte de cada persona esta reprogramada de acuerdo a la biología y es la descomposición de un organismo y la pérdida de la estructura orgánica. Para Pedro Laín cuando el cuerpo muere, el hombre muere (Paramo 2010, 569). Si la muerte es una reprogramación biológica, ¿y quién lo reprograma? Asimismo, ¿cómo queda la persona humana en esa descomposición orgánica o hay algo más? De igual forma, si el hombre es esencialmente su cuerpo, 
¿desaparece totalmente éste con la muerte o permanece algo en él? Platón definió la muerte como separación del alma y del cuerpo. Heidegger, en el ser y el tiempo, -que por el contenido es una obra más antropológica que metafísica- sostiene que el Dasein o el hombre está arrojado en el cosmos y es un ser para la muerte. Según (Arocha 2020,97) es el hecho más grave e inalcanzable de la existencia humana.

También es notable considerar la muerte social como un morir para la sociedad racista, consumista, egoísta y orgullosa:

"La muerte social es el efecto de una práctica social en la que una persona o grupo de personas es excluido, dominado o humillado hasta el punto de convertirse en muerto para el resto de la sociedad. Aunque tales personas están físicamente vivas, sus vidas ya no tienen un significado social; ya no cuentan como vidas que importan. Los muertos sociales pueden hablar, actuar, componer sinfonias o encontrar una cura para el cáncer, pero sus palabras y hechos no tienen importancia". (Guenther 2013, 20).

Es el momento de replantearnos algunas cuestiones relevantes a partir de esta pandemia. ¿Qué significa, por ejemplo, ser vivo? ¿La muerte es simplemente un desaparecer de este mundo o también existe una "muerte en vida" o la muerte social? ¿Todo se acaba con el devenir de la muerte o hay algo que permanece? ¿O existe otra vida más allá de este mundo? ¿Si todo acaba con la muerte, vale la pena vivir? Si existe otra vida, debemos aprender cada día a ser mejores personas.

Asimismo, qué vida nos conviene vivir después de la pandemia. Puesto que, de alguna manera, hemos estado viviendo la vida incluso con algunos excesos. Según Aristóteles, la vida buena -que en idioma quechua es allin kawsay o sumaq kawsay- es un estilo de vida basado 
en las virtudes ${ }^{6}$ (Ethica Nichomaquea 1215a 9-14). Tiene como su ornato los valores de la honestidad, sencillez, solidaridad, la empatía, la servicialidad, el cultivo de la inteligencia espiritual y la alegría de vivir. Según Amartya Sen los valores en torno a lo que se considera una "vida buena" están enmarcados en un plano social y cultural (Restrepo 2013, 2375). Mientras que, la buena vida se apoya en la sensualidad, esto es, en la satisfacción de placeres corporales. Es alimentada constantemente por la estructura de la sociedad de consumo. Buscar la mayor cantidad de placeres y evitar en lo posible el dolor o sufrimiento. O, como decía Epicuro, "bebamos y comamos que mañana moriremos". Disfrutar del momento de placer, el carpe diem, buscando el placer por el placer.

Ahora bien, quizá nos conviene replantearnos un nuevo estilo de vida, que nos ayude a vivir la felicidad en este mundo, aunque sea relativa. ¡Que valga la pena! Siendo cada vez, más humanos y mejores personas consigo mismo, la familia y la sociedad y dejar a un lado las "apariencias" e intentar a vivir cada día una vida más auténtica.

\subsection{El deterioro de la salud mental y espiritual}

El confinamiento social, al cual estamos obligados para evitar los contagios, golpea fuertemente, a la vez, en el aspecto emocional y equilibrio o salud mental de las personas; ocasionando altos niveles de estrés, tristeza, ansiedad y angustia. (Huarcaya 2020, 327-334). Entonces, no sólo es cuidarnos físicamente para no contagiarnos, sino evitar y superar estos estados de ánimo. Se presenta una dificultad: ¿Cómo se puede articular el confinamiento social obligatorio y la salud mental o espiritual; puesto que ya llevamos varios meses en esta

\footnotetext{
${ }^{6}$ Cfr. 1217a 28-29; 1217b 24-25; 1219a 25; En quechua estos términos denotan el modus vivendi de una manera específica. Allin kawsay significa vivir con bondad en todos los ámbitos, sin hacer daño a nadie. Y el sumaq kawsay: una vida hermosa basada en las virtudes. Es costumbre en Huancavelica, que a los recién casados se les recomienda formar una familia basada en el respeto, amor y comprensión.
} 
situación? Podemos estar sanos físicamente y enfermos espiritualmente. Como sabemos existen también enfermedades del alma o espíritu.

Por otra parte, el hombre es el único ser en la tierra que está adornado en su identidad ontológica con "complejísimas joyas": biológico, psíquico, emocional, espiritual y trascendencia. Cuesta mucho articular lo material o fisiológico con lo espiritual. Esto se puede considerar como uno de los enigmas del ser humano. Según la antropología cartesiana, la razón y las emociones mantienen una relación aislada, como sabemos entre el alma y el cuerpo hay una relación accidental, pues son "sustancias independientes e irreductibles entre sî” (Páramo 2010, 564). No obstante, hoy en día, esto está superado. La inteligencia y la toma de decisiones está íntimamente relacionada con las emociones (Llanes 2013, 300). Ahora bien, ¿hasta qué punto pueden influir nuestras emociones en nuestra forma de pensar? Las emociones positivas ensanchan el conocimiento intelectual, pero las negativas, bloquean la capacidad racional. Dicho de otro modo, si estamos afectados emocionalmente, lo lógico nuestro pensamiento tendrá unas consecuencias. No es lo mismo una emoción de la alegría y tranquilidad que hacen brillar las ideas; a diferencia de la tristeza y el enfado que ofuscan la mente humana. La inteligencia es como una ventana para ver la realidad. Las emociones son como las cortinas o persianas. Si bajamos las persianas a las ventanas, veremos todo oscuro. ¡Necesitamos tener una mentalidad positiva más que nunca!

Es importante enlazar bien todas las dimensiones humanas, especialmente, lo emocional con el pensamiento. No podemos pecar por exceso: por un lado, siendo demasiados racionalistas, cuadriculados y aislando a un lado las emociones; por otro, siendo demasiados sentimentales y subordinando el pensamiento a las emociones. Es significativo actuar inteligentemente, sin embargo, dando un valor 
positivo a los estados de ánimo. Por algo, dijo Pascal que "el corazón tiene razones que la razón no puede comprender".

En el hombre, la parte sensitiva está muy relacionada con lo espiritual. Así, para conocer o inteligir necesitamos -la experiencia- la fantasía (Suárez 1991, n.2); lo mismo para amar y actuar necesitamos las emociones. En fin, si éstas determinan lo que somos, lo que deseamos o no deseamos ser. Es un campo de investigación fascinante.

\subsection{El caos en el presente y el futuro incierto}

Nuestra sociedad, ya por sí, estaba dominada por la incertidumbre (Martínez 2012, 97) y esta pandemia aún ha complicado esta situación. En esta crisis mundial, el orden brilla por su ausencia. Parece que todo es de color negro, una noche oscura. No sabemos qué hacer ahora y cómo salir de esto. ¡Hay una desesperación de parte de la población! Es elemental destacar el bloqueo psicológico que ocasiona la pandemia, pues, fue un duro golpe para la mente, al menos al principio. A esto, del mismo modo, se va sumando más problemas o dificultades de todo tipo, a parte de los que ya teníamos. Los problemas familiares, económicos, psicológicos y morales, se juntan como un montículo de arena y empiezan a pesar más.

La incertidumbre es la falta de completa seguridad y se distingue de la ignorancia -privación de conocimiento- porque somos seres limitados (Romero 2020, 178). Aún, en esta crisis, la incertidumbre es mayor. E1 futuro es incierto. No sabemos realmente qué es lo que nos espera en el mundo venidero. Como dicen algunos: ¡no sabemos qué va a pasar, solamente Dios sabe! Nada es predecible. ¡Solo esperar que todo esto mejore! Además, no hay que olvidar que la incertidumbre es parte integrante de nuestras vidas con y sin pandemia. 
Con todo, necesitamos el orden y una luz en la mente -que alumbre algo este mundo de oscuridad- esto es, algunas "ideas claras y distintas" para afrontar el problema como seres inteligentes. Para Descartes, el orden es un método. Éste es lo que nos hace falta. ¿Qué pasa, si falta esa luz a nuestra inteligencia y de modo particular a los que dirigen el destino del país, región y provincia? En esta coyuntura, realmente echamos de menos a nuestras autoridades: la sabiduría para gobernar; la fortaleza para enfrentar los problemas y el liderazgo para dirigir a buen destino como el rey Salomón.

Teniendo en cuenta, que el homo sapiens, fue la única especie, que ha salido de todas las dificultades, hay una gran esperanza, de que todo esto cambie, para un buen puerto.

\subsection{Desenmascaramiento de la corrupción}

La corrupción y la falta de transparencia están en su máxima expresión, está campeando a todo nivel. ¡Es la peor pandemia de todos los tiempos y hasta el momento no se halla ninguna vacuna! Enfocamos solamente en el campo de salud y educación, que son los principales pilares del desarrollo de una nación, y las ayudas económicas. Señalemos algunos factores, que propiciaron este hecho inmoral en las instituciones estatales en este tiempo: la rapidez con la que debian realizar "las compras de bienes y servicios, las necesidades de la población y las flexibilizaciones de los procesos de contratación estatal" (Madrid y Palomino 2020, 228).

\subsubsection{La precariedad del sistema salud}

No hubo ningún hospital del mundo que haya hecho frente al coronavirus, casi todos han colapsado e incluso los mejores. ¡Nadie ha 
estado preparado, mucho menos el Perú! Como manifiesta (Maguiña 2020, 08) a nivel nacional: los "hospitales viejos, falta de materiales, laboratorios especializados, camas, ventiladores, especialistas, y una población geriátrica abandonada, médicos mal remunerados, sin seguro médico, y como nunca, falta de equipos de bioseguridad para combatir a este nuevo flagelo". Y concretamente, Huancavelica se encuentra en condiciones efimeras, a pocos gobernantes les ha importado y si les ha interesado no lo han hecho bien. Esto no es por falta de dinero, sino simplemente por la carencia de honestidad. A veces, la vida es injusta; ya que los profesionales de la salud no perciben como se merecen. Como dijo una médica española que los futbolistas ganan sumas exorbitantes, empero, en una pandemia de esta naturaleza no enfrentan ellos sino los médicos.

Destaquemos, las compras irregulares de los implementos de bioseguridad, equipos médicos, productos de limpieza y aseo personal, servicios de alimentación y otros. Como es el caso del Centro Nacional de Abastecimiento de Recursos Estratégicos en Salud (CENARES) el cual fue intervenido por presuntas irregularidades en la compra de 1'257,900 unidades de mascarillas N-95, destinadas al personal de salud por el coronavirus. Donde, según la Contraloria, el total de dinero invertido era de 24 millones 654 mil 840 soles, por lo que deducen, se habría ahorrado más de 4 millones de soles. (Zavaleta y Chávez 2020, 5) Pero no se sabe dónde han parado los cuatro millones. Es para indignarse, ni la emergencia sanitaria ha detenido la lacra de la corrupción, de algunos malos elementos que han buscado su propio beneficio.

El otro hecho de corrupción lamentable es manifestado en el Ministerio del Interior: la compra de mascarillas, artículos de limpieza para los efectivos policiales en este estado de emergencia. Que 
sobrevaloraron el precio del jabón antibacterial, jabón en barra, alcohol en gel, lejía, y compras a sus allegados o familiares más cercanos ${ }^{7}$.

Los gobiernos regionales están en las mismas condiciones han demostrado su ineficacia, solo buscando sacar, provecho de cualquier situación. Otra perla son los gobiernos locales -municipalidades provinciales, distritales y centro poblados-, aprovecharon y buscaron lucrarse, favoreciendo a sus amigos y familiares cercanos, no llegando a apoyar a los más necesitados, como está estipulado en las directivas.

\subsubsection{La precariedad de la educación virtual}

La educación también es afectada por la pandemia. Se implantó a nivel nacional las clases por vía virtual. Para la cual se "requiere de nuevos métodos, un permanente diálogo y vinculación en busca de puntos de intersección especialmente en el desarrollo personal -Inteligencia emocional- de los estudiantes y su vinculación con las tecnologías de la información" (Guardia 2020, 13).

Mas, no todos tienen acceso al internet ni tienen ordenadores o laptops. Esta situación es más notoria en las zonas andinas y en los pueblos del territorio huancavelicano. En esta grave situación el gobierno ha prometido la compra de las tablets para los estudiantes de zonas rurales incorporado con internet. Pero hasta ahora no se ha hecho realidad.

Otro punto a considerar, ¿cuánto invierte el Estado en la educación? ¿Qué tipo de educación queremos los padres para nuestros hijos? ¿Los docentes que han invertido su tiempo y su talento en su formación

\footnotetext{
7 La adquisición productos de forma irregular por el monto de S/ 800 mil soles, en Lima, sin embargo, estas acciones delictivas se habría hecho costumbre en las distintas regiones del país, como informó la procuraduría que el $51 \%$ del total se han dado en las siguientes regiones: Áncash, Lima, Arequipa, La Libertad, Junín, Ayacucho y Cajamarca. Como también se puede cotejar del programa emitido por ATV DIA “D”, 24 de mayo del 2020.
} 
perciben lo que les corresponde? Si el Estado ha apostado por ella, tiene todo el derecho de exigirlos. Sólo pensar cuanto tiene que invertir económicamente para estar cada día bien formado: tener una buena biblioteca, capacitaciones, y si tiene familia. El sueldo que percibe cubre todo esto, y le ayuda a vivir dignamente como cualquier profesional. $\mathrm{Si}$ un maestro trabaja en los pueblos alejados cuánto gasta en alimentación, viajes y hospedaje. No es lo mismo ejercer la docencia en una zona urbana que rural. Sería ideal que perciban buenos sueldos que cubra todas sus necesidades vitales. Después sí exigirles que dicten buenas clases, que estén bien formados, rindan los exámenes. Porque donde hay un deber está a su lado el derecho, ambos son correlativos.

Finalmente, es algo paradójico en el sistema de educación peruana, se necesita profundizar más. En el Diseño Curricular Nacional Básica, ocupa un lugar central la formación ética en valores, a pesar de ello, lamentablemente, no se imparte este curso y mucho menos el curso de filosofia en las II.EE. de nivel secundario desde los tiempos del ex presidente Alberto Fujimori. Para salir de cualquier crisis, especialmente como de la coyuntura actual, necesitamos personas pensantes con mentalidad abierta y valores. Por esta razón, es necesario fomentar el desarrollo del pensamiento crítico por medio de la filosofia y ética (Guardia 2020, 13).

\subsubsection{El gobierno y la ayuda humanitaria}

El gobierno central transfirió a los alcaldes de las distintas municipalidades de todo el país la suma de S/ 200 millones, para que ayudaran a las personas más vulnerables. Con todo, en la administración de este apoyo económico en una situación tan grave, ha pasado de todo con el dinero del Estado, mejor dicho, con el dinero del pueblo y de todos. 
Lo más dramático, después de más de un mes, solo había usado el más responsable el 60 por ciento. Si han repartido, pero no a la gente necesitada, sino a sus amigos y familiares e incluso a los mismos funcionarios públicos ${ }^{8}$ (Zavaleta y Chávez 2020, 8). En algunos municipios fue realmente una miseria o una burla. Incluso obtuvieron estos productos a precios sobrevalorados. En muchas municipalidades, han recibido los que realmente no necesitan la ayuda humanitaria.

Asimismo, el Estado dio apoyos económicos a las familias vulnerables que se quedaron sin trabajo, -el 70 por ciento son trabajadores informales- que vivían del trabajo día a día. Destacamos el Bono Yo me quedo en casa, el Bono Independiente, el Bono Rural y el Bono Familiar Universal. Lo más triste, esta subvención monetaria del gobierno llegó con "una yapa de coronavirus" en las mismas palabras del presidente Vizcarra por la falta de coordinación y aglomeración en los bancos.

En suma, los subsidios monetarios del gobierno han sido tan lentos como la tortuga -usando la paradoja de Zenón de Elea- y el COVID-19 tan rápido como Aquiles, en esta guerra. Esta ayuda para las personas vulnerables fue una buena iniciativa, en cambio, no ha sido eficaz por una mala gestión.

\section{El individualismo y el colectivismo andino}

Toda sociedad tiene una forma de pensar, sentir y actuar (Chanca, Ávila y Aliaga 2020, 72). Y ésta es parte integrante de los principales valores positivos, que aún se practican en las comunidades rurales de los andes centrales del país -primordialmente en Huancavelica y sus

\footnotetext{
${ }^{8}$ Según informe de la Contraloría General de la República del 23 de junio del 2020, a nivel nacional más de 4212 funcionarios públicos habrían sido beneficiados con las canastas familiares; en Lima 180 funcionarios, en Callao 136, Piura 120 y Junín 87 funcionarios.
} 
comunidades- como son: el trabajo y la amistad, (Pérez, Espinosa y Beramendi, 2014, 158). A pesar de ello, también existen valores negativos como: desidia, la envidia y el egoísmo. Estos valores son elementos centrales de una cultura donde prima el colectivismo y la ayuda mutua, que garantiza el bienestar y la armonía de cada uno de sus integrantes dentro de la comunidad, a la cual (Sahua 2007, 21) lo denomina la vida en armonía entre las diferencias, mientras que (Huanacuni 2010, 13) habla del buen vivir, que nuestros antepasados lo conocian como el allin kawsay.

El colectivismo andino que aún pervive en nuestras sociedades rurales de la sierra central del Perú, expresado en la reciprocidad y el apoyo mutuo como uno de los principios fundamentales, donde aún prevalece la propiedad comunitaria de la tierra que otorga nuevas formas de relacionamiento en el uso de los recursos -suelo, agua y otros- en su mayoría está sujeta a la participación y trabajo comunitario, donde aún pervive la solidaridad, o como (Sánchez 1987, 30) denomina ayni a la reciprocidad entre campesinos pobres y minka entre campesinos pobres y ricos, la reciprocidad se basa en el principio de señalar que "para recibir, primero hay que dar", prácticas colectivas creadas y recreadas por las familias y organizaciones rurales que son expresadas en las diversas actividades económicas, sociales, culturales y politicas, sobre la cual se organiza y gestiona la sociedad rural como hereditaria de los ancestros.

Por otra parte, tenemos una sociedad urbana donde prima los fieles hereditarios de occidente: se fomenta el "desarrollo", término atractivo que está fortaleciendo el individualismo, el libre mercado, el consumismo y la contaminación. Donde el pobre se hace cada vez más pobre y el rico, más rico. Frente a esta situación, se han creado e implementado una serie de programas sociales con la finalidad de solucionar el problema. 
Aunque, en vez de ser una ayuda positiva, algunas veces se agudiza más porque se implementan modelos o recetas ajenas que no compatibilizan ni funcionan en nuestra realidad social.

En este contexto de la pandemia generada por el COVID-19, hay un resurgimiento de estas prácticas colectivas dentro de las sociedades urbanas. Las cuales muestran una serie de prácticas y acciones organización y gestión-, que conllevan a afrontar este problema desde los migrantes andinos, que se hallan hacinados en su mayoría en los barrios marginales de las grandes ciudades. Donde se asentaron, a pesar de las peripecias, vicisitudes e inclemencias que afrontan. Por el orgullo de manifestar que "vivo en la ciudad", donde no cuentan con los servicios básicos: agua, luz y el desagüe. Quienes pasan a formar directamente el sector de extrema pobreza, por el abandono de los gobiernos de turno. Con todo ello, no se entiende, ¿cómo estos peruanos no hayan sido registrados y atendidos por los diversos programas sociales?

Las diversas problemáticas vividas y que se observan a través de los medios de comunicación -en estos tiempos de pandemia donde se manifiestan negativamente- generan el resurgimiento del sistema de reciprocidad andina, que hoy se puede expresar como el colectivismo popular. Este conlleva a muchas familias necesitadas a organizarse de diversas formas de sobrevivencia: comedores populares, canastas familiares y otros, para hacer frente a esta problemática latente del hambre y la miseria. Además de ello, se observa que hay muchas empresas privadas, instituciones y organizaciones de migrantes, que vienen apoyando, a través, de donaciones de productos de primera necesidad como viveres y ropas. En otras palabras, es el resurgimiento de la reciprocidad y solidaridad que se organiza y gestiona la vida, económica, social y cultural de los pueblos. 
Pero también tenemos por otra parte las opiniones contrarias que a esta forma de gestión y organización cuestionan considerándolas retrasadas y/o barreras culturales al cambio como refiere (Foster 1964, 100).

\section{Declive del cientificismo naturalista e iluminista}

Parecía que en estos dos últimos siglos, como sostuvieron Sartre y Nietzsche, la humanidad ya no necesitaba de ningún Ser Supremo porque su existencia era incompatible con la libertad humana y "Dios había muerto" como asevera en el parágrafo 125 de La Gaya Ciencia (Aliaga 2019, 139). La existencia de este Ser era una alienación por la necesidad material como sostuvo Marx o como los intérpretes de Darwin, para quienes el hombre proviene del mono por casualidad sin intervención de una inteligencia superior. Según Fiske, "el gran cambio que se avecinaba y que sería posible sólo gracias a Darwin, consistía en que por fin el hombre se iba a liberar definitivamente de la religión" (Tarnawski 2009, 219). En el regreso de su primer viaje a la luna -ya que su segundo periplo fue sin retorno-, el astronauta Yuri Gagarin declaró su postura atea, según Nikita Jruschev, Secretario General de Partido Comunista, en un discurso: "Gagarin voló al espacio, pero no vio ningún Dios allï. En algunos lugares del mundo han optado por un estado "laico", sacando a Dios de su conciencia y de la sociedad, en último término, de sus vidas.

Fue notorio el avance de la ciencia a pasos agigantados y, a la vez, lineal. La ciencia ha dado aportaciones novedosas a la humanidad. Esto es loable. Algunas veces antagónicamente, este progreso científico trató de manipular o experimentar con embriones humanos, saltándose los parámetros éticos. Otras veces, se saltó a otro ámbito para especular y 
sacar conclusiones, por ejemplo, que existe sólo la realidad material no así lo espiritual. Este cientificismo tiene en el fondo un cuño materialista e iluminista9 (Tello 2020, 7). Por ende, en este mundo de "naturalismo mecanicista" ya no hay un lugar para realidades trascendentales. Pero esta ciencia mal entendida o fisicalismo fue sorprendida por el COVID19. Detalles por describir: muchos hospitales colapsaron, miles de personales de salud infectados $\mathrm{y}$ fallecidos, no hay medicamentos específicos para combatir este virus. Es paradójico: un coronavirus que se muere con un simple lavado de jabón y agua, la ciencia mecanicista no puede controlar esta pandemia con todos los avances científicos. Y ¿quiénes hacen la ciencia? Los grandes científicos son humanos y conscientes de sus limitaciones, no hacen especulaciones hipotéticas, dogmatistas o reduccionistas, cuidan al máximo el rigor científico. Pero como individuos finitos y con inteligencia limitada, algunas veces pueden equivocarse.

Por otra parte, a pesar de las bondades que ofrece el progreso científico y tecnológico en estos tiempos. Cabe preguntarnos: ¿una tecnología mal usada no es una forma de esclavitud moderna? ¿Nos estamos convirtiendo en "esclavos", por ejemplo, de los celulares? ¿Qué mundo nos espera después de la pandemia, no será un mundo virtual y podremos adecuarnos a él con responsabilidad?

\section{Conclusión}

La experiencia fenomenológica de la situación del COVID -19 en Huancavelica, expresa realmente la pobreza extrema, la precariedad del sistema sanitario, el nivel alto de ignorancia, la falta de liderazgo de las autoridades y partidos políticos -que para las campañas políticas

\footnotetext{
${ }^{9}$ El Iluminismo es la filosofía que identifica la verdad con el sistema científico.
} 
despilfarran muchísimo dinero, empero, brilla su ausencia en esta coyuntura-. Es destacable la labor de la Iglesia católica, que ha podido llegar con la ayuda humanitaria a muchos pueblos de la localidad e incluso mejor que las autoridades locales, regionales y nacionales. Asimismo, la educación principalmente en las zonas rurales no ha sido fructífera por la falta de recursos para comprar computadoras, laptops o tablets y el internet, y las promesas del gobierno incumplidas. Además, muchos pueblos de Huancavelica no tienen acceso a la energía eléctrica mucho menos al internet. Es necesario la presencia del gobierno en esta zona; y que se invierta más en la salud y en la educación a nivel nacional, que son dos pilares fundamentales para el desarrollo de un pueblo.

Del mismo modo, esta situación amerita una reflexión sobre temas relevantes para la humanidad. Puesto que en lo esencial todos los hombres somos iguales, aunque hay diferencias accidentales que aún prevalecen en lo económico, político, social y cultural. Esta situación concreta y específica nos ayuda atrevernos a pensar y pausadamente, sobre el sentido de la vida, sabiendo que un día vamos a dejar de existir. La muerte, realmente es una situación muy dolorosa. Hasta ahora es inexplicable y sigue siendo aún un enigma para el hombre. Después de esta situación avizoramos muchos cambios en todos los aspectos de la vida humana, ¿Qué sucederá en el campo filosófico?

Desde la perspectiva antropológica, podemos señalar algunas cuestiones generadas por el COVID-19: la situación del confinamiento global, paralización de la mayor parte de la economía mundial y cómo ha transformado nuestro modus vivendi a nivel familiar, organizacional e institucional. En algunos aspectos, se observa un volver a vivir las prácticas y costumbres ancestrales de los pueblos andinos; por otro lado, es conveniente resaltar que los ritos funerarios -como tradición aglomeraba familiares, amistades del difunto- han sido trastocados, por 
los protocolos de cremación e inhumación que se realizaron en "soledad"; impidiendo las prácticas de un entierro digno, según las costumbres tradicionales. Es loable resaltar el proceso de adaptación a los nuevos sistemas de comunicación y uso de tecnologias en los diversos sectores de la población; dado que la pandemia visibilizo nuestra fragilidad para enfrentar las situaciones adversas, para el cual no estuvimos preparados.

Finalmente, es oportuno reconocer, que, hemos fracasado como sociedad civil. Por las razones expuestas, del cual Huancavelica no es ajeno; debido a la irresponsabilidad y el cuidado de los "pequeños detalles" mostrada por las autoridades y la población en general. 


\section{Referencias}

Aliaga, O. D. C. (2019). "Dios ha muerto" y la cuestión de la ciencia en Nietzsche. Estudios de Filosofia, (59), 139-166.

Aristóteles (1985). Ética Nicomaquea, Introducción por Emilio Lledó Iñigo; Traducción y notas por Julio Palli Bonet, Gredos, Madrid.

Arocha, J. G. (2020). Filosofia y Muerte Social en Tiempos de Covid-19. Dialektika: Revista de Investigación Filosófica y Teoría Social, 2(4), 95-100.

Badiou, A. (2020). En sopa de Wuhan, pensamiento contemporáneo en tiempos de pandemias. 67-78

Boitano, A. (2020). Noción de crisis: acepciones, límites y actualidad del concepto. Mutatis Mutandis: Revista Internacional de Filosofia, 1(14), 11-29.

Chanca Flores, A., Ávila Mendoza, J., \& Aliaga Caynicela, M. Y. (2020). Percepción cultural de los pobladores sobre el Programa Social Juntos en el Valle del Mantaro. Socialium, 4(1), 68-83.

https://doi.org/ 10.26490/uncp.s1.2020.4.1.510

Contraloría General de la Republica (mayo - junio 2020). Boletín de Contraloría en acción, Edición $\mathrm{N}^{\circ}$ 17 (Págs. 2-3)

Decreto Supremo N 044-2020-PCM (Diario Oficial El Peruano 15 de marzo de 2020).

Foster, G. M. (1964). Las culturas tradicionales y los cambios técnicos. Sección de Obras de Antropologia.

Guardia, S. B. (2020). Educación y pandemia. el reto de una formación humanística y ética.

Educación y Pandemia, 9.

Guenther, L. (2013). Solitary Confinement: Social Death and Its Afterlives. Minneapolis: University of Minnesota Press https://doi.org/10.5749/minnesota/9780816679584.001.0001

Guillen, D. G. (1994). Dilemas actuales de la ética médica ante opciones vida-muerte. Cuadernos de sección. Ciencias médicas, 3, 143-154.

Han, Byug -Chul. (2020). En Sopa de Wuhan. La emergencia viral y el mundo de mañana. Buenos Aires, Argentina: ASPO. 110

Huanacuni Mamani, F. (2010). Buen vivir/Vivir bien. Filosofia, políticas, estrategias y experiencias regionales andinas Lima: Págs. 57-58

Huarcaya-Victoria, J. (2020). Consideraciones sobre la salud mental en la pandemia de COVID-19. Revista Peruana de Medicina Experimental y Salud Pública, 37(2).

https://doi.org/10.17843/rpmesp.2020.372.5419

Llanes, J. E. M., Benítez, H. A. U., Chan, A. M. P., Cetina, F. E. P., \& Gómez, M. A. B. (2013). Burnout en personal administrativo de una institución de educación superior tecnológica de Yucatán, México. Revista Electrónica de Psicología Iztacala, 16(3), 741-763.

Madrid-Valerio, C., \& Palomino-Ramírez, W. (2020). Oportunidades de corrupción y pandemia: el compliance gubernamental como un protector eficaz al interior de las organizaciones públicas. Desde el Sur, 12(1), 213-239. https://doi.org/10.21142//DES-1201-2020-0014

Maguiña-Vargas, C. (2020). Reflections on COVID-19 infection, Colegio Medico del Peru and the Public Health. Acta Médica Peruana, 37(1), 8-10. https://doi.org/10.35663/amp.2020.371.929

Martínez-García, J. I. (2012). Derecho e incertidumbre. Anuario de Filosofia de Derecho. Pp. 97-118. 
Noemi, J. (2007). Vida y muerte: una reflexión teológico-fundamental. Teología y vida, 48(1), 41-55. https:/ /doi.org/ 10.4067/S0049-34492007000100004

Páramo-Valero, V. (2012). El eterno dualismo antropológico alma-cuerpo: ¿roto por Laín? Thémata. Revista de Filosofia, 46, 563-569.

Pérez-Salinas, B., Espinosa, A., \& Beramendi, M. (2014). Metas de bienestar y valores en una comunidad rural andina de Puno-Perú. Revista colombiana de psicología, 23(1), 149-161. https://doi.org/10.15446/rcp.v23n1.30834

Portal Central, (14 de abril de 2020). Declaraciones; Maciste Díaz, "paisanos que caminan"

Resolución Ministerial Nº97-2020-PCM (Diario Oficial El Peruano 16 de abril de 2020)

Restrepo-Ochoa, D. A. (2013). La salud y la vida buena: aportes del enfoque de las capacidades de Amartya Sen para el razonamiento ético en salud pública. Cuadernos de Saúde Pública, 29, 2371 2382. https://doi.org/10.1590/0102-311X00069913

Romero, C. (2020). ¿Cómo puede contribuir la filosofia de la ciencia en la crisis del COVID-19?, Scientia in verba Mag. 6, pp. 178-186

Sahua-Zambrano, J. (2007). La doctrina secreta de los incas." Huancayo. Perú: CAESAN

Sánchez-Enríquez, R. (1987). Organización andina, drama y posibilidad. Vol. 1. Instituto Regional de Ecología Andina.

Suárez, F. 1991. Commentaria una cum quaestionibus in libros Aristotelis De anima. Tomo III. Madrid: Fundación Xavier Zubiri.

Tarnawski, E. (2009). El "cosmista" Stalin y el "socialismo del siglo XXI". Cuadernos De Pensamiento Politico, (22), 211-242. Retrieved October 3, 2020, from http://www.jstor.org/stable/25597214

Tello, Á. P. (2020). Iluminismo y pandemia: certezas e incertidumbre. Boletín del Departamento de Seguridad y Defensa.

Zavaleta-Davis, J. J., \& Chavez-Santivañez, L. A. (2020). Corrupción en la gestión de recursos públicos asignados en la emergencia sanitaria COVID-19 en el gobierno regional de La Libertad Perú 2020 https://doi.org/10.47192/rcs.v1i2.30

Žižek, S. (2020). Coronavirus es un golpe al capitalismo al estilo de 'Kill Bill'y podría conducir a la reinvención del comunismo. Sopa de Wuhan: Pensamiento contemporáneo en tiempos de pandemia, 21-28. 